\title{
Morphospace: Measurement, Modeling, Mathematics, and Meaning
}

\author{
N. Khiripet ${ }^{1}$, R. Viruchpintu ${ }^{1}$, J. Maneewattanapluk ${ }^{1}$, \\ J. Spangenberg ${ }^{2}$ and J. R. Jungck ${ }^{3 *}$ \\ ${ }^{1}$ Bioinformatics Unit, Knowledge Elicitation and Archiving Laboratory (KEA) \\ NECTEC (National Electronics and Computer Technology Center), Thailand Science Park \\ 112 Phahonyothin Road, Klong 1, Klong Luang, Pathumthani 12120, Thailand \\ ${ }^{2}$ Department of Biology, Washington State University, Pullman, WA 99164 \\ ${ }^{3}$ Department of Biology, Beloit College, 700 College Street, Beloit, WI 53511
}

\begin{abstract}
Artists have long recognized that trees are self-similar across enormous differences in magnitudes; i.e., they share a common fractal structure - a trunk subdivides into branches which subdivide into more branches which eventually terminate in leaves, flowers, fruits, etc. Artistid Lindenmayer $(1971,1975,1989,1990)$ invented a mathematics based on graph grammar rewriting systems to describe such iteratively branching structures; these were named in honor of him and are referred to as L-systems. With the advent of fractals into computer graphics, numerous artists have similarly produced a wide variety of software packages to illustrate the beauty of fractal/Lsystem generated plants. Some tree visualizations such as L-Peach (Allen et al., 2005) do depend very explicitly upon a complex set of precise measurements of a single species of tree. Nonetheless, we felt that there is a need to build a package that allowed scientists (and students) to collect data from actual specimens in the field or laboratory, insert these measurements into an L-system package, and then visually compare actual trees to the computer generated image with such specimens. Furthermore, the effect of variance in parameters helps users evaluate the developmental plasticity both within and between species and varieties. We have developed 3 D FractaL Tree (the $\mathrm{L}$ is capitalized in honor of Lindemayer) to generate trees based upon measurement of (1) relative lengths of two successive segments averaged over several iterations, (2) the angle theta between bifurcating limbs at successive joints, (3) the number of steps in branching that one must follow to find a branch extending at the same angle as the first one under consideration to determine the phyllotactic angle phi, (4) the average of the summed areas (determined from measurement of diameters) of bifurcations compared to the trunk to determine whether area of flow is preserved (and
\end{abstract}

\footnotetext{
*Corresponding author. E-mail: jungck@beloit.edu
} 
to consider Poiseuille's/Murray's law of laminar flow in a fractal network), (5) the total number of iterative branching from the base to the tip of tree averaged over several counts based on following out different major limbs, (6) an editable L-system rule chosen from a library of branching patterns that roughly correspond to a specimen under consideration, and (7) a degree of stochasticity applied to the above rules to represent some variation over the course of a lifetime. Of course, turned upside down, the computer imagery could be used to represent root structure instead of above ground growth or the bronchial system of a lung, for example. The measurements are recorded and analyzed in a series of worksheets in Microsoft Excel and the results are entered into the graphics engine in a Java application. 3D FractaL Tree produces a rotatable three-dimensional image of the tree which is helpful for examining such characters as self-avoidance (entanglement and breakage), reception of and penetration of sunlight, distances that small herbivores (such as caterpillars) would have to traverse to go from one tip to another, allometric relationships between the convex hull of the crown (as perceived in a top-down projection of the tree) and the trunk's diameter, and convex hull of the volume distribution of biomass on different subsections of a tree which have been discussed in the Adaptive Geometry of Trees (Horn, 1971) and subsequent research for the past four decades. Besides being able to rotate the three dimensional tree in the $x-y$, $\mathrm{y}-\mathrm{z}$, and $\mathrm{x}-\mathrm{z}$ planes as well as zoom-in and zoom-out, three different representations are available in $3 D$ FractaL Tree images: wire frame, solid, and transparent. Easy options for editing L-system rules and saving and exporting images are included. 3D FractaL-Tree is published with a Creative Commons license so that it is freely available for downloading, use, and extending with attribution from our Biological ESTEEM Project (http://bioquest.org/esteem).

Key words: plant architecture, morphospace, multivariate-multidimensional modeling, 3D tree visualization, education, allometry, Lindenmayer systems, graph grammars, fractals, computational geometry, convex hulls, creative commons

AMS subject classification: $92 \mathrm{C} 80$

\section{Introduction}

Three dimensional computer visualization of artificial life plants have predominantly focused on developing an aesthetic sensibility that appears realistic (Prusinkiewicz and Lindenmayer, 1991) and is used extensively in movie scene construction, landscape architecture, horticulture, and computer gaming, but a whole field within plant science has developed that regularly holds international conferences (see Seits et al., 2004; FSPM07,2007). While the field has grown rapidly over the past forty years (Lindenmayer published one of the first models in 1968), very little of this literature and the tools developed by these researchers has reached the majority of botanists, much less the undergraduate curriculum. Furthermore, most packages that are currently available are neither easily amenable to working with measurements from actual specimens nor reflecting back from measurements on the theoretically produced model. We have developed a software package, $3 D$ 
FractaL Tree, that has been specifically designed for general use to address both of these problems. We believe that there are four extraordinarily important motivations for constructing artificial life models of trees that users can directly correspond to measurements that they have made on actual specimens:

(1) First, students need to think of plants as problem solving organisms within both their biotic and physical environment and that their geometries reflect such selective pressures (Horn, 1971; Honda, 1971; Hogeweg and Hesper, 1974). This phytocentric perspective moves students beyond the 5F's of anthropocentric botany (food, fuel, fiber, fragrance, and pharmacology) to consider questions about how a plant is surviving in its surroundings: e.g., How much light penetrates through a canopy? Do terminal ends of branches avoid self-shading? Does the architecture mechanically support large loads under stress? Are there trade-offs between vertical growth and internal constraints on mechanical stresses of wind, rain, snow pack, etc.? Are there allometric relationships between crown area and trunk diameter? How does a fractal structure relate to the flow of fluid throughout a whole tree? If we examine clonal plants packed close together, such as aspens or sumac, how does their topology differ from trees in an "oak opening" on a prairie hill near a river? By relating measurements that they have taken and analyzing this data with quantitative tests, they report that they never thought of understanding the world from another organism's perspective of solving problems in its environment, particularly non-charismatic, non-sessile organisms like many plants. We introduce game theoretic models (Mesterton-Gibbons and Childress, 1996) to ask them to consider decisions like cooperating or competing or moving to transfer from individual trees to spatial distributions of neighboring plants and such phenomena as canopy gaps.

(2) Second, the National Research Council published a document entitled Bio 2010 (2003) with an executive summary of eight points; the first two of these emphasized that more mathematics needs to be included in the education of all life scientists. Also, in Science 2020 (e.g., Szalay and Gray, 2006), the only recommendation that was repeated four times in a complex overview broken into three five-year segments was that in 2005, 2010, 2015, and 2020 was "education - how to produce 'new kinds' of scientists now urgently needed (computationally and mathematically highly literate." We argue that most biologists and biology students need extensive experience in using a wide variety of mathematical models so that they appreciate the significance of causalbased reasoning, hypothesis testing, quantitative analysis and experimental design (Cohen, 2004; Jungck, 1997, 2005, 2008; Weisstein et al., 2007). Three dimensional tree models are a complex mixture of biological data, concepts, and mathematics; experience in interactively engaging all three is highly likely to be beneficial to students as well as scientists in visualizing the relationships between measurements, causes, and models.

(3) Third, too much of science education, even laboratory-rich education, is conducted indoors and does not engage students in the analysis of organisms within their immediate environment. A strong advantage of focusing on trees is that most campuses have a sufficient variety and quantity of vegetation to support the kinds of hands-on, minds-on activities described herein. Particularly in northern temperature zones, it affords a particularly good outdoor experience with winter trees as the phytoarchitecture is so dramatically transparent. As the award winning educator, Carol Brewer, University of Montana, said in receiving the AIBS Education Award (2007) celebrated the educational initiative to: "Leave no child inside." Richard Louv (2008; Knapp, 2009) described 
the general movement as the emerging Children \& Nature Network (http://www.cnaturenet.org). In Seeing Nature: Deliberate Encounters with the Visible World, Paul Krafel (1999) argues that the combination of scientific models and outdoor experiences are transformative in public comprehension of paradigm shifts:

One night I saw the Earth turning. Before that night, I had always seen the Sun setting toward a stationary horizon. But when I saw the Sun, instead, as stationary, then I saw my horizon rising toward the Sun. In my first view, the Sun moves. In the second view, my world moves. My eyes see the same thing - the gap between the Sun and the horizon closing. Yet what is moving? My mind must make an assumption. Shifting that assumption changes the world I see.

Similarly, the paleontologist Adolph Seilacher (in Willis, 1995) said: "I wouldn't have seen it, unless I believed it." The role of mathematical theory as a lens that allows us to see observables omnipresent, but never-to-fore taken into conscious consideration, is a significant development for many students and non-mathematically inclined biologists. The heuristic role of models in helping us plan experiments, make appropriate measurements, and iteratively improve our understanding of causal factors that underly patterns that we see often involves a Gestalt shift. Our students certainly report such major shifts in their perspective. The art historian and visual anthropologist James Elkins (1996) summarizes their experiences very well: "Ultimately, seeing alters the thing that is seen and transforms the seer. Seeing is metamorphosis, not mechanism."

(4) Fourth, theoretical biology is often missing from biology education and receives even less attention than mathematics. Sattler and Rutishauser (1997) identify nine major advances in the theoretical understanding of plant morphogenesis in the past thirty (now forty) years. Their first two are highlighted herein: L-systems and fractals. Not only do students need to understand the application of mathematics to biology, they also need to understand that the synergistic and reciprocal exploration of totally new mathematics is stimulated by attempts to understand nature. Theoretical biology embraces both and helps students examine their basic assumptions and conceptual understandings as well as exposing them to controversies among working scientists who infer very different causal relationships for what they and others have observed. We believe that this is important to students appreciating the role of peer review and creativity as well as heterodoxy within the scientific community rather than a singular textbook "received view."

(5) Fifth, students initially presume that abstract models and rich visual representations are "just models," "pretty pictures," or too elementary to be of any practical use. They are surprised to learn that Lindenmayer models have real world applications such as pruning to produce yield in peach orchards (Grossman et al., 2003), landscape architectural planning of vegetation around homes in architecture, ... Wegrzyn et al. (1990) state that such "model[s], despite [their] simplicity, can account for a great number of properties of living organisms, e. g., their hierarchical structure, their ability to regenerate after a trauma, the possibility of cloning, their sensitivity to mutation, their growth, decay and reproduction. The model lends itself to analysis: the knowledge of the generating word makes it possible to predict the structure of the successive developmental stages of the system; and to synthesis: a specific type of structure can be obtained by systematically constructing a generating word that produces it." These two aspects of analysis and synthesis 
have proven to be effective agents in generating students' changes in perspective as well. Thus, modeling becomes an iterative social process in their learning.

\section{Goals of 3D FractaL Tree}

Thus, 3D FractaL Tree has been specifically designed for general use to address all five of these problems and is a robust three-dimensional visualization software application key to fully exploiting the power of theoretical tree models. We believe that our model successfully addresses three common challenges to computer visualization (Breiman, 1995):

Scientific integrity - does the model of a particular tree represent what we know and what we infer from our knowledge of the relationship of form and function?

Visual integrity - does the model give the visual impression of (i.e., provide a close corresponding match) the tree that we took measurements and would like to portray?

Data integrity - is the model free from data duplication and errors, are the relationships properly defined?

Henceforth, we present a student exercise for collecting data, visualizing the correlate data in $3 D$ FractaL Tree, some underlying principles of $3 D$ FractaL Tree model, extension of the model to considerations of Morphospace, and finally some suggestions for more extensive use of $3 D$ FractaL Tree than simple individual classroom use.

\section{Activity: Fractal Tree Generation and Analysis}

This activity if an extension of a lab exercise described verbally in 1982 by Henry Horn, Princeton University, that he used with a two dimensional program and many fewer parameters. It encouraged students to break off a twig that looked self-similar to the tree under consideration. We prefer to send the message that the organism be studied in situ via non-destructive techniques and that multiple sample measures be performed both within a branch, over multiple branches within a given tree, that multiple individuals of the same species or variety be considered, and then that multiple species and varieties be compared.

- Digitally photograph a tree free of leaves (a beauty of conducting an outdoor lab in winter in both Northern and Southern temperate zones of the earth): (each group should focus on a different type of tree on campus - the Beloit College campus has oaks, maples, shag bark hickories, gingkos, horse chesnuts, walnut, lilac, dogwood, rosebud, honey locust, etc. -the NECTEC campus being set in the tropics has an even wider diversity of mature trees, but without a winter the lush vegetation actually makes it a little harder to complete this project - nonetheless, we illustrate two Thai trees herein as examples: Plumeria and Kajong trees - while many of the trees are extraordinarily beautiful, we suggest that users focus on some of the very recently planted nursery trees or an individual limb of a mature tree that has not been pruned and that has an overall appearance similar to the whole tree under consideration - they are much shorter, younger, competing less with neighbors around them, and easy to view from many perspectives. 
- Each group of three student collaborators should measure six parameters with a tape measure and a protractor on your individual tree according to Figure 1:

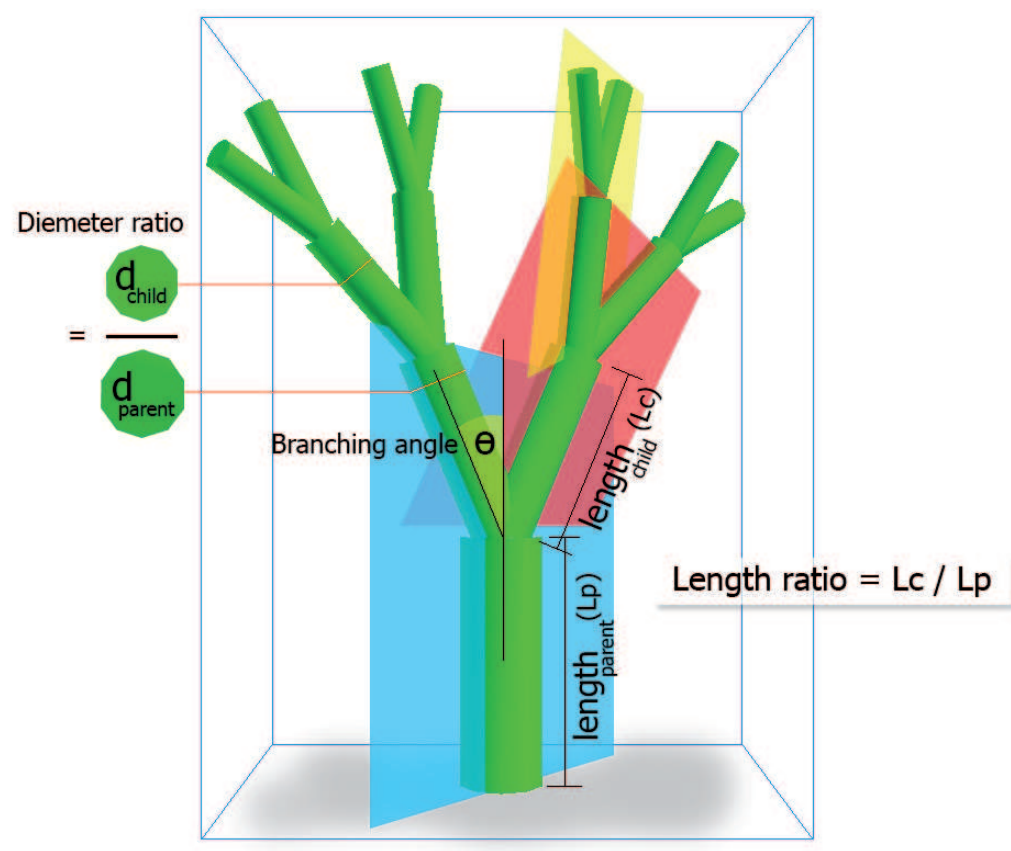

Figure 1: To generate a fractal tree from actual measurements, five sets of measurements are taken. These include determination of: (i) the ratio of child $\mathrm{L}_{c}$ to parent $\mathrm{L}_{p}$ branch lengths; (ii) the ratio of child $\mathrm{d}_{c}$ to parent $\mathrm{d}_{p}$ branch diameters; (iii) the angle theta of inclination of each child branch to the vertical axis plane of parent branch (the vertical axis plane is perpendicular to the midplane that goes through both daughter branches; (iv) the angle phi of phyllotaxis (defined by how many times do branches eminate from the current branch before finding a branch parallel to the branch projected; and (v) the number of iterations needed to capture the form (we are limied by screen resolution, however, this usually doesn't cause a significant problem in the visualization - we have tried to illustrate the twisting of the tree with differently colored planes.

- (1) five successive lengths of consecutive segments;

- (2) five successive diameters of consecutive segments;

- (3) the branch angles of five successive bifurcations;

- (4) the phyllotactic angles (by counting the number of branches that you need to ascend to go completely around to superimpose at the same angle in 3D space as a branch below) of five successive bifurcations;

- (5) the number of iterations from base to terminal tip; and, 
- (6) choose the L-system rule that generates a tree most like yours (these are stored in $3 D$ FractaL Tree and are described in the next section below), or choose several rules and the stochastic probability such as one-third rule $\mathrm{x}$ and two- thirds rule $\mathrm{y}$, or write your own L-system rule by consulting Prusinkiewicz and Lindenmayer (1990).

- Enter all your values in the ESTEEM Excel spreadsheet (Downloadable from (http://www.bioquest.org/esteem/).

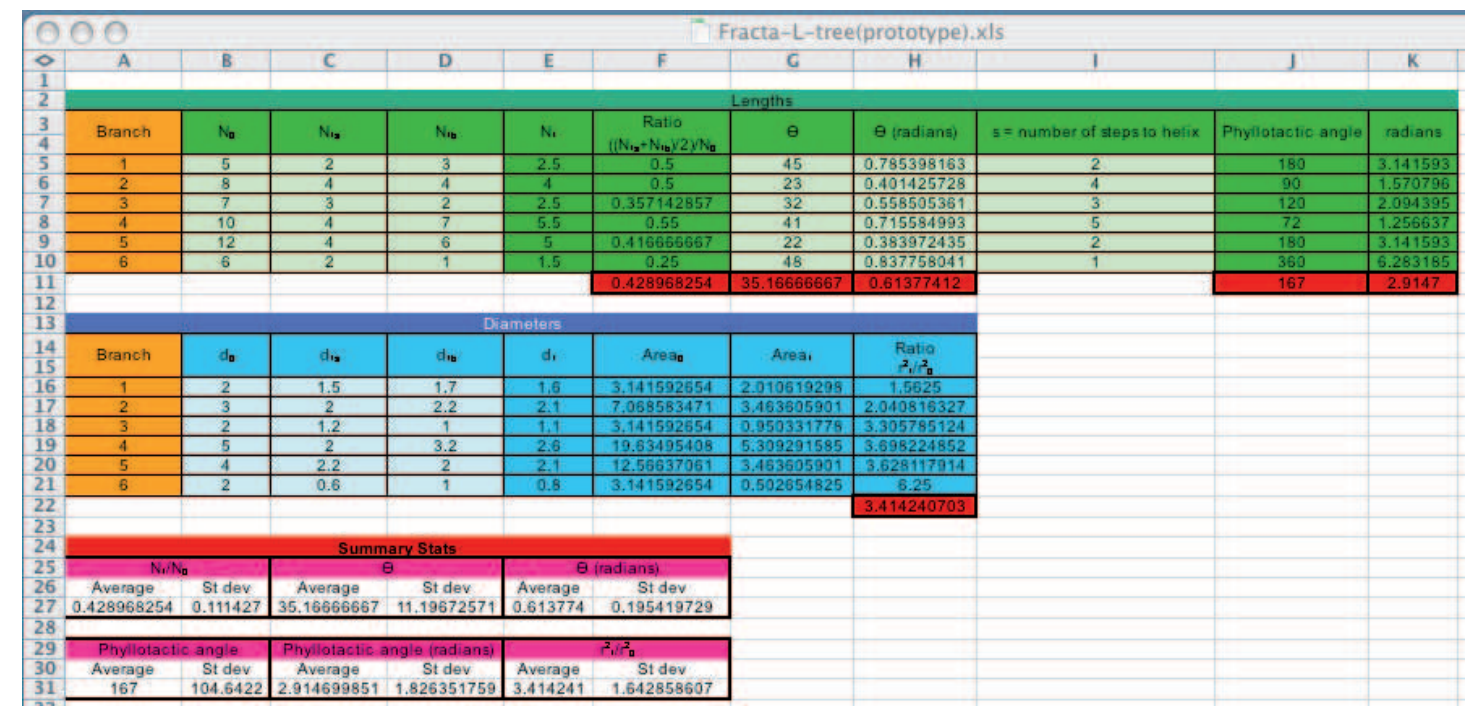

Figure 2: Screenshot of 3D FractaL Tree accompanying Excel spreadsheet (only one page of several - this one is for a strictly bifurcating tree - other pages are for tri- and tetra-furcations as well as for more stochastically varying observed tree shapes). Users can enter data for all measurements described above and the spreadsheet will execute averages for each variable. These averages are then entered into 3D FractaL Tree interface for the actual visualization.

- Enter the ESTEEM Excel spreadsheet calculated values into the table on the right hand pane of the ESTEEM Java applet (see Figure 3) "3D FractaL Tree" (Also downloadable from (http://bioquest.org/esteem/) to generate your virtual tree (keep a screen shot of this image and its values).

- Slightly adjust your parameters to see whether you can make the image better match your photographed tree; iterate until it looks "good."

- Determine the area of a "convex hull" of the canopy (make a planar top down view of your virtual tree; import this picture into Image $\mathrm{J}$ to compute it or do manually with a triangulation approach). [Image $\mathbf{J}$ is available in Mac, PC, and Linux versions for free download from: rsbweb.nih.gov/ij/download.html] Figure 4 illustrates such a top down projection compared to a head on view. 


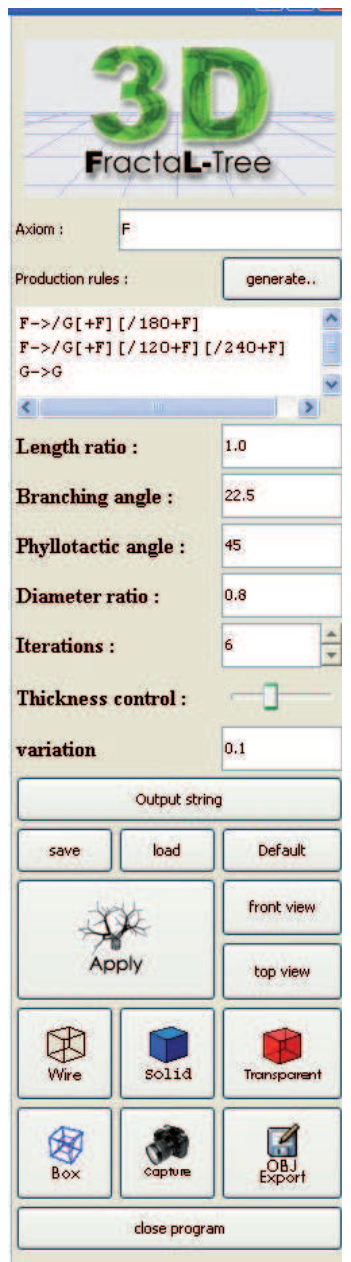

Figure 3: Panel for entry of initial values from measurements on right hand screen.
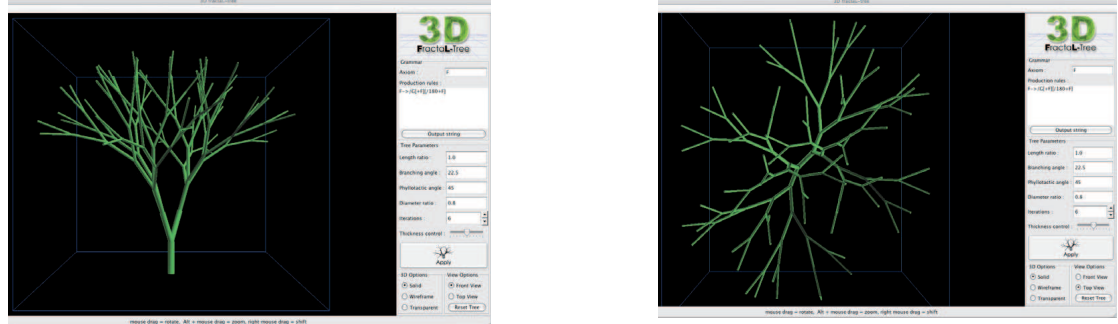

Figure 4: (a) Head on view of a generated tree. (b) Top down projection of the same tree as in 4a. 
- Develop both an exponential and log equation relationship between the basal trunk area and canopy area; what is the significance of this relationship biomechanically? (Horn, 1971)

- Test whether area of cross section is preserved at bifurcations. (see Bessonov and Volpert, 2008) for an excellent analysis of the assumption of area preservation pre- and post-branching; they report four sets of measurements that demonstrate area preservation $r_{1}^{2}+r_{2}^{2}=r_{0}^{2}$ within a few percent: (1) $6,7,9,85 \mathrm{E}$ vs $81 \mathrm{O}$; (2)9, 10, 13.5, 181E vs 182.25 ; (3) 8.5, 11.5, 14.5, 204.5E vs 210.25O; (4) trifurcation: $r_{1}^{2}+r_{2}^{2}+r_{3}^{2}=r_{0}^{2}: 5,8,9.5,13,179.25 E$ vs 1690 ). How does this relate to water transport? (see McCulloh et al., 2003, 2004 and Aratsu, 1998.)

- Additional possible extension project: Do linear regression of number of bifurcations from trunk to terminal bifurcation versus number of rings in tree core sample. [A large variety of tutorials on methods are available from the MARV4/2 photogrammetric inventory 2007; Published March 30, 2007 - Last modified June 2, 2007. Available at: www.helsinki.fi/ korpela].

- Additional possible extension project: Use the stochastic version of $3 D$ FractaL Tree to generate a slightly more realistic (that is with more internal variation) approximation of your tree. Compute the volume of a three dimensional convex hull around a set of different major branches. Compare the volumes and the number of branches within those convex hulls and relate these measurements to allocation of biomass in your model. Hiratsuka et al. (2003) have an allometric equation for estimating above ground biomass that we have found works approximately as a first estimate for a variety of trees. Brian Enquist and Karl Niklas (2002) review a more theoretical approach to allometric relations between "intraspecific and interspecific scaling relationships among seed plant leaf, stem, and root biomass."

- What may be operating in the arrangement of your limbs (e.g., avoiding self-shading)?

- Your poster should have a title, authors (with asterisk by presenter's name), a clear introduction, images, tables, analysis section, conclusion - discussion, and references.

- One of the three members of your group should serve as presenter and two should be peer reviewers of posters by other members of the class.

\section{Modeling}

Modeling objects with mathematical and computational tools is always a crucial step in understanding the real process and situation. In biological domain, such as plant modeling, this requires biological knowledge of plant physiology along with mathematical formalism and computer graphic.

\section{Graphics overview}

There has been an active research area in modeling plant using Lindenmayer $(1971,1975,2004)$ Systems that simplifies the plant shape as a 3D object. The object is defined by a self-similarity 
grammar. Many currently existing tools can facilitate the generating of grammar to represent any particular plant. For example, L-System Generation Program (LSystem4) [L-System Generation Program (LSystem4), http://www.trjjw.com/Lsystem4/L4Home.htm] is a 3D visualization tool which offers enhanced options for viewing 3D models such as rotation and movement control, texture mapping per layers and visible assignment of textures to layers. J. Scott Cameron has shown the wonderful 3D L-Systems application [3D L-Systems (Direct3D), http://www.alesdar.org/ oldSite/IS/chap4-4.html] to model the growth of trees. His L-system was nicely implemented by the use of Microsoft's Direct3D API to show the skeleton of the tree structure. LYNDYHOP [http://www.lab4web.com/chelmiger/lyndyhop/lh_start.html] is a simple Java-Application for generating self-similar fractals in 2D graphics step by step. The program also provides a graphical representation of the rules, which helps to understand the growth of the pattern. Another application is the Floradig software [http://www.cpai.uq.edu.au/], which can record 3D coordinates and then convert them into geometric properties such as the internode length and the angle between the main stem and branches. It also uses linear and non-linear regressions to fit the data and provides geometrical attributes for the plant model.

However, we believe that what is missing from the traditional L-System modeling approach is the sense of what is really going on in nature. In stead of doing trials and errors in adjusting L-System parameters and inventing grammars until the resulting 3D plant object looks like the actual plant, could these actual parameters be taken from the plant and be integrated into a simple grammar? In doing so, the final output object should represent not only the plant, but, also how much we learn from the nature in denerating the plant. Furthermore, the tool could allow real-time user interaction to help visualize the 3D object.

Our 3D FractaL Tree system consists of four modules as depicted in Figure 5. Starting with L-system generator, the axiom and rules are constructed to form a new string as defined by an L-systems concept. Next, the coordinates and directions of the model are generated by a Turtle interpreter module followed by decorating the rough model using Geometry Generator [http://www.cs.brown.edu/exploratories/freeSoftware/repository/edu/brown/cs/exploratories/ components/java3d/geometryGenerator/cube_geometry_generator_guide.html] and 3D Renderer [www.3drender.com/] module. The decorated model is made interactive by 3D Renderer. Optionally, the standard format for the other 3D tools is made possible by the Wave-front OBJ Generator.

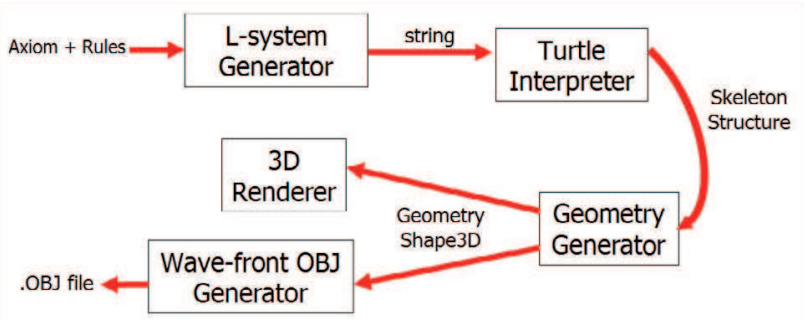

Figure 5: Components of the FractaL-Tree system. 


\section{Lindenmayer systems}

An L-system is a grammar that is used to generate a new grammatical string by rewriting an old string (complex patterns are generated by successively replacing parts of a simpler pattern by using a set of rewriting rules or production rules) and following the syntax of production rules.

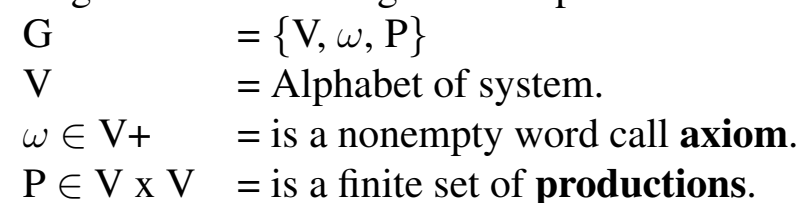

A production $(\mathrm{a}, \mathrm{X}) \in \mathrm{P}$ is written as a $->\mathrm{X}$

The letter a and $\mathrm{X}$ are called the predecessor and the successor of production.

The following example shows the simulation of the development of a fragment of a multicellular filament found in the blue-green bacteria, Anabaena catenula and various algae (Prusinkiewicz and Lindenmayer, 1990). The filaments appear as a sequence of cylinders with a-type cells longer than b-type cells. To be manipulated by L-systems, the variables $a$ and $b$ are used to represent cytological states of the cells (their size and readiness to divide). The subscripts $l$ and $r$ indicate cell polarity, specifying the positions in which daughter cells of type $a$ and $b$ will be produced. The following rules describe the development process of the filament:

$$
\begin{aligned}
& \omega: a r \\
& p 1: a r \rightarrow a l b r \\
& p 2: a l \rightarrow b l a r \\
& p 3: b r \rightarrow a r \\
& p 4: b l \rightarrow a l
\end{aligned}
$$

Starting from a single cell ar (axiom), the following sequence of words is generated:

ar

albr

blarar

alalbralbr

blarblararblarar

The strings represent the structure of organism at each iteration as shown in Figure 6.

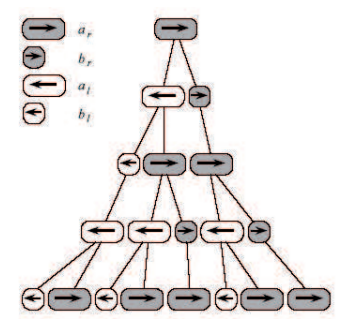

Figure 6: Development of a filament (Anabaena catenula) simulated by L-system (Prusinkiewicz and Lindenmayer, 1990). 


\section{3D Turtle interpretation}

The output string from L-system is interpreted into a 3D object structure by mapping each alphabet in the string into direction and operation of a turtle traveling in 3D space as displayed in Figure 7.

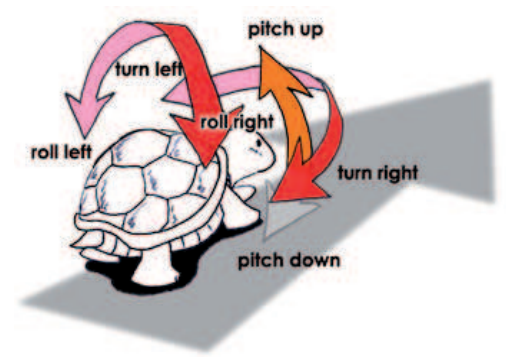

Figure 7: Turtle traveling in 3D space. Note the differences between pitch, roll, and turn.

The following operations control the turtle orientation in 3D space:

$+\quad$ Turn left by angle $\alpha$, using rotation matrix $\mathbf{R U}(\alpha)$.

- Turn right by angle $\alpha$, using rotation matrix $\mathbf{R U}(-\alpha)$.

$\&$ Pitch down by angle $\alpha$, using rotation matrix $\mathbf{R} \mathbf{L}(\alpha)$.

A Pitch up by angle $\alpha$, using rotation matrix $\mathbf{R L}(-\alpha)$.

$\backslash$ Roll left by angle $\alpha$, using rotation matrix $\mathbf{R H}(\alpha)$.

/ Roll right by angle $\alpha$, using rotation matrix $\mathbf{R H}(-\alpha)$.

I Turn around, using rotation matrix $\mathbf{R U}\left(180^{\circ}\right)$.

The orientation of the turtle in space can be represented by three vectors $H, L$, and $U$, indicating the turtle's heading, the direction to the left (or right), and the direction up (or down). Where $\mathrm{R}$ is a $3 \times 3$ rotation matrix. Specifically, rotations by angle $\alpha$ about vectors $\mathrm{U}, \mathrm{L}$ and $\mathrm{H}$ are represented by the matrices in Figure 8 .

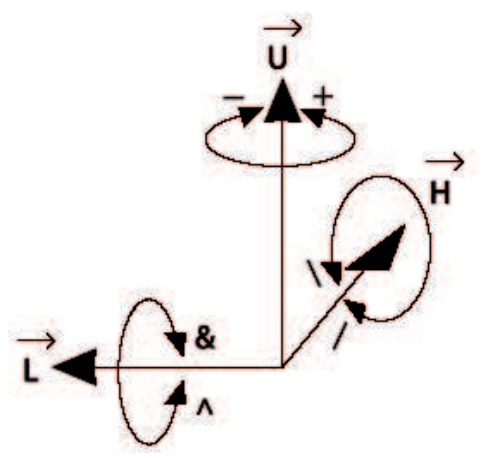

$$
\begin{aligned}
& {\left[\begin{array}{lll}
\vec{H}^{\prime} & \overrightarrow{L^{\prime}} & \overrightarrow{U^{\prime}}
\end{array}\right]=\left[\begin{array}{lll}
\vec{H} & \vec{L} & \vec{U}
\end{array}\right] \mathbf{R},} \\
& \mathbf{R}_{\mathbf{U}}(\alpha)=\left[\begin{array}{ccc}
\cos \alpha & \sin \alpha & 0 \\
-\sin \alpha & \cos \alpha & 0 \\
0 & 0 & 1
\end{array}\right] \\
& \mathbf{R}_{\mathbf{L}}(\alpha)=\left[\begin{array}{ccc}
\cos \alpha & 0 & -\sin \alpha \\
0 & 1 & 0 \\
\sin \alpha & 0 & \cos \alpha
\end{array}\right] \\
& \mathbf{R}_{\mathbf{H}}(\alpha)=\left[\begin{array}{ccc}
1 & 0 & 0 \\
0 & \cos \alpha & -\sin \alpha \\
0 & \sin \alpha & \cos \alpha
\end{array}\right]
\end{aligned}
$$

Figure 8: Spatial 3D rotation matrices. 


\section{Plant parameter description}

An actual plant usually consists of many parts such as branches, trunks, leaves and flowers. To simplify the modeling task without losing much of reality, we will focus only on branches and trunks, and ignore the rest. We start by observing the self-similar characteristics of a plant, then we take a couple of real measurements as described in Figure 1 and below in Figure 9.
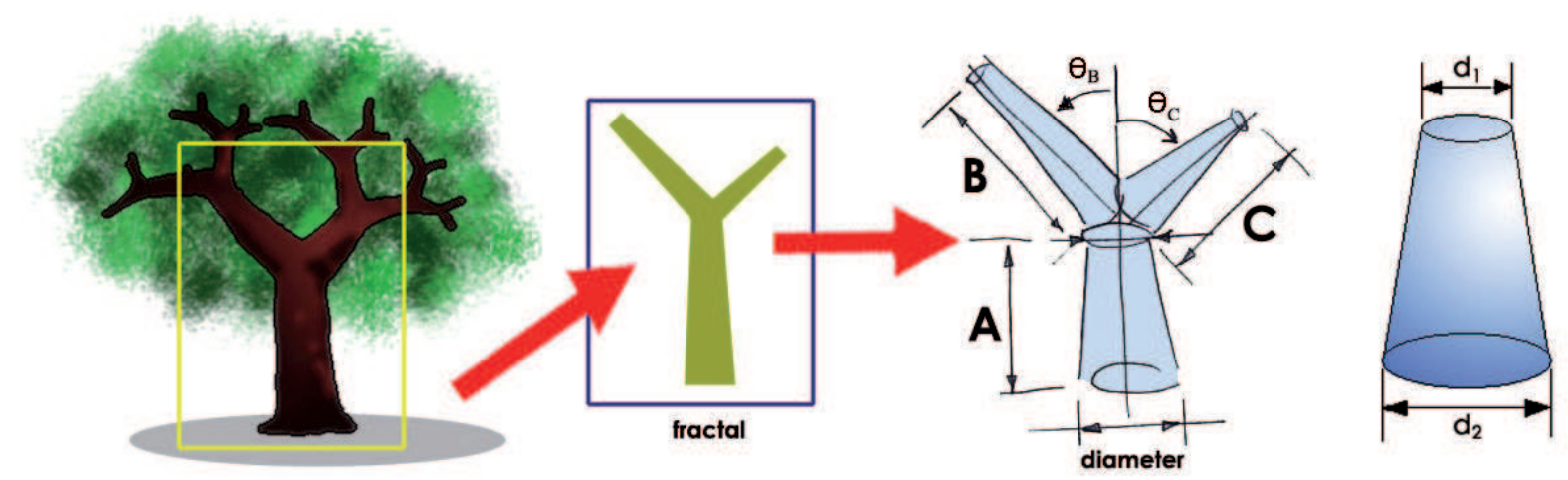

Figure 9: This composite series examines self-similar pieces of a tree for measurement. This illustrates another diameter that we can use if substantial tapering is occurring between the base of a trunk and the first branching. For the trees being considered in this paper, we are not illustrating this feature as part of our current release as posted on the BioQUEST website.

We defined the grammar used with the example plant as follows:

$\begin{array}{ll}\text { Axiom: } & \text { F } \\ \text { Production rules: } & \text { F -> GG [-GF] [+F] } \\ \text { Phyllotactic angle: } & 45 \\ \text { Branch angle: } & 45\end{array}$

The parameters are defined as follows:

Length ratio: The proportion between the length of parent and a child branch. From the example tree in Figure 1, the proportions between the branch length from the real tree are transferred into two fractions, $\mathrm{B} / \mathrm{A}$ and $\mathrm{C} / \mathrm{A}$ which are 1 and $1 / 2$. The production rule is defined as $\mathrm{F}->\mathrm{GG}$ [-GF] $[+\mathrm{F}]$, corresponding to them while branches $\mathrm{A}, \mathrm{B}$, and $\mathrm{C}$ are represented by strings $\mathrm{GG},-\mathrm{GF}$ and $+\mathrm{F}$. The number of alphabets in an equivalent string are assigned to each branch length, length $\mathrm{A}$ $=2$; length $\mathrm{B}=2$; and length $\mathrm{C}=1$. By the examination, this production rule yields the proportion of the real tree.

Branching angle $(\Theta)$ : The angle between parent branch and each child branch (Figure $1 \& 9$ ).

Phyllotactic angle $(\Phi)$ : The angle between the plane of children branches (self-similarily pattern) and the plane of parent branch (Figure 1).

Diameter ratio: The parameter used to adjust the diameter size of each successive child branch compared to its parent branch $\left(\mathrm{d}_{\text {child }} / \mathrm{d}_{\text {parent }}\right.$ in Figure 1$)$. 


\section{Visualization development}

The visualization application of development was implemented by Java3D technology, a standard extension to the Java 2 JDK [Dennis J Bouview, Java 3D API Tutorials, [http://java.sun.com/products/java-media/3D/collateral/index.html]. This API provides a collection of high-level constructs for creating and manipulating 3D geometry and for structures rendering that geometry. It was designed for non-expert developers using packages provided for creating geometric models, visualizations, animations and interactive 3D objects. Other advantages of Java are that it is a convenient language for the creation of GUI applications and that the performance of rendering 3D geometry is quite fast for display detail of model in real-time.

\subsection{Geometry Generator}

The coordinates, surfaces and meshes defining branches in space were added to the skeleton structure. The amount of the vertices controls the resolution of the plant model and increases the computational tasks. The shape of the plant is adjusted as following: The bottom diameter of the parent branch is proportion to the diameter and the number of the children branches; The top diameter of each branch is decreased from the bottom in proportion to the diameter ratio.

\subsection{User Navigation \& 3D Renderer}

This module is designed for user interaction. The plant model can be viewed in four modes with different surfaces: polygon, hidden surface polygon, solid, and transparent. Moreover, a user can interact with the model through the provided menu functions such as zoom in, zoom out, rotate, reset the best view, show or hide the boundary box, capture the image, export model to Wave-front OBJ file format, and adjust parameters for real-time simulation.

\subsection{Wave-front OBJ Generator}

There are practical options for using the model in other 3D rendering software. We implemented the export engine for converting objects to standard 3D objects text based file format that is compatible with Wave-front OBJ file format [Wave-front and Java3D .OBJ Format, http://www.javaview.de /guide/formats/Format_Obj.html]. This format supports both polygonal and Free-form geometry (curves and surfaces).

\section{Experiment}

Target plants with adequate self-similarity characteristics were chosen. Information obtained from the measurements is listed below (Table I) and the plant parameters were calculated according to these values. 


\section{Example 1: Alstonia scholaris tree.}

Table 1: Plant parameters from a Alstonia scholaris tree used in this project.

$\begin{array}{ll}\text { Parameters } & \text { Value } \\ \text { Length ratio } & 8 / 12 \\ \text { Branching angle } & 48,40,40,40 \\ \text { Phyllotactic angle } & 56 \\ \text { Diameter ratio } & 0.95\end{array}$

From these parameter values, we generated the L-system:

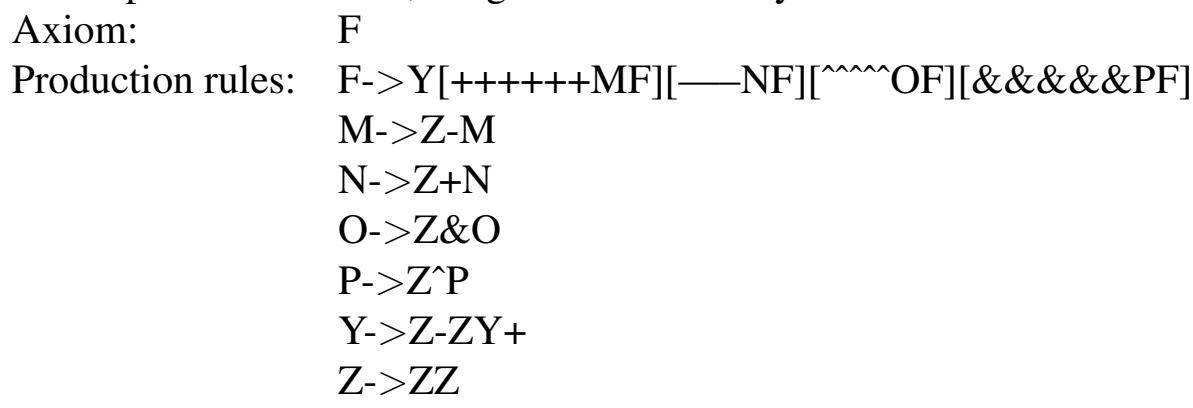

The grammar was put into the $3 D$ FractaL-Tree program as illustrated in Figure 10 and results in plant structures proceeded by each iteration as shown in Figure 11.

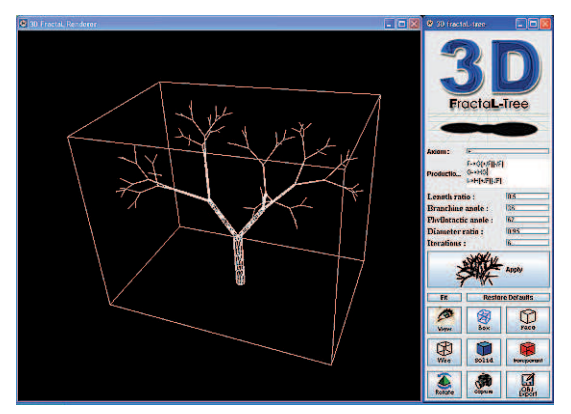

Figure 10: A screenshot of the 3D FractaL-Tree program with a model of an Alstonia scholaris tree.

Figure 11 shows the originally measured plant and compares it to the constructed model. The model differs from the real plant slightly in the amount of angle between the trunk and some branches.

We illustrate the versatility of $3 D$ FractaL Tree by showing a couple actual trees versus their models, a couple models (Examples 4 and 5) are included without the real plant, to demonstrate some examples known to most readers. 


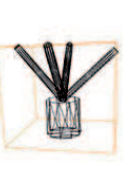

iteration 1

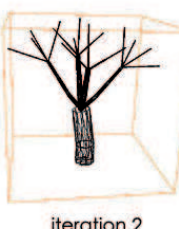

iteration 2

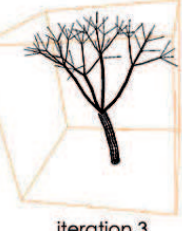

iteration 3

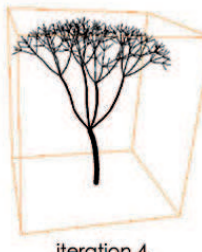

iteration 4

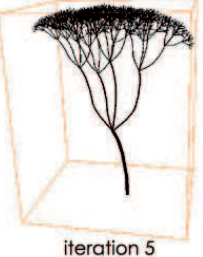

iteration 5

Figure 11: The structure of the example plant constructed by 3D FractaL Tree from iteration 1 to 5.

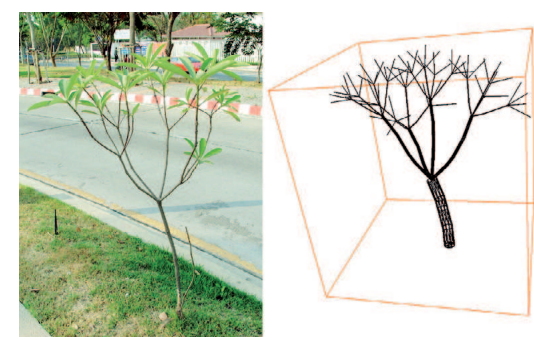

Figure 12: An actual biological tree compared to its constructed model in 3D FractaL Tree.

Example 2: One of the first challenges to us came from users who did not think that this approach would work with pines in multilayers. Thus, we chose a tropical tree with similar architecture called a Krajong tree (Figure 13).
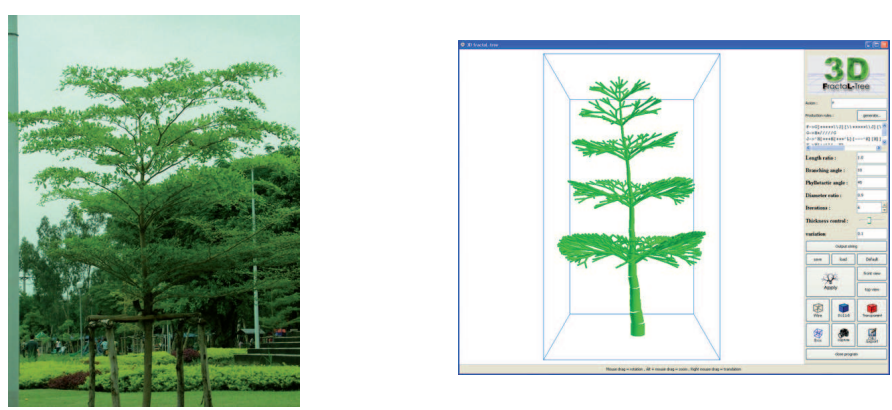

Figure 13: (a) A Krajong tree on the NECTEC campus and (b) the computer model.

The L-system rules used for the Krajong tree are: [HOOKRAJONG_TREE.TXT file; [plant parameters]; length ratio $=1.0$; branching angle $=10$; phyllotactic angle $=45$; diameter ratio $=0.9$; iteration=6; axiom=F; [grammar] F- $>\mathrm{G}[+++++\backslash \backslash \mathrm{J}][\backslash \backslash+++++\backslash \backslash \mathrm{J}][\backslash \backslash \backslash \backslash \backslash+++++\backslash \backslash \mathrm{J}][/ /+++++\backslash \backslash \mathrm{J}] / \mathrm{F}$; $\mathrm{G}->\mathrm{H}+/ / / / / \mathrm{G} ; \mathrm{J}->^{\wedge} \mathrm{H}\left[+++\mathrm{H}\left[+++{ }^{\wedge} \mathrm{L}\right]\left[-{ }^{\wedge} \mathrm{K}\right][\mathrm{H}]\right]\left[-\mathrm{H}\left[+++{ }^{\wedge} \mathrm{L}\right]\left[-^{\wedge} \mathrm{K}\right]\right][\mathrm{H}] ; \mathrm{K}->\mathrm{H}[++\mathrm{L}][-\mathrm{K}]$; $\mathrm{L}->\mathrm{H}[++\mathrm{L}][-\mathrm{K}][\mathrm{H}]]$.

We also used the Krajong tree to illustrate an additional feature of $3 D$ FractaL Tree, namely; The ability to export the 3D model into other software packages that can handle 3D objects in artic environments (see Figure 14). This feature is especially attractive to art, film, and theater majors. 

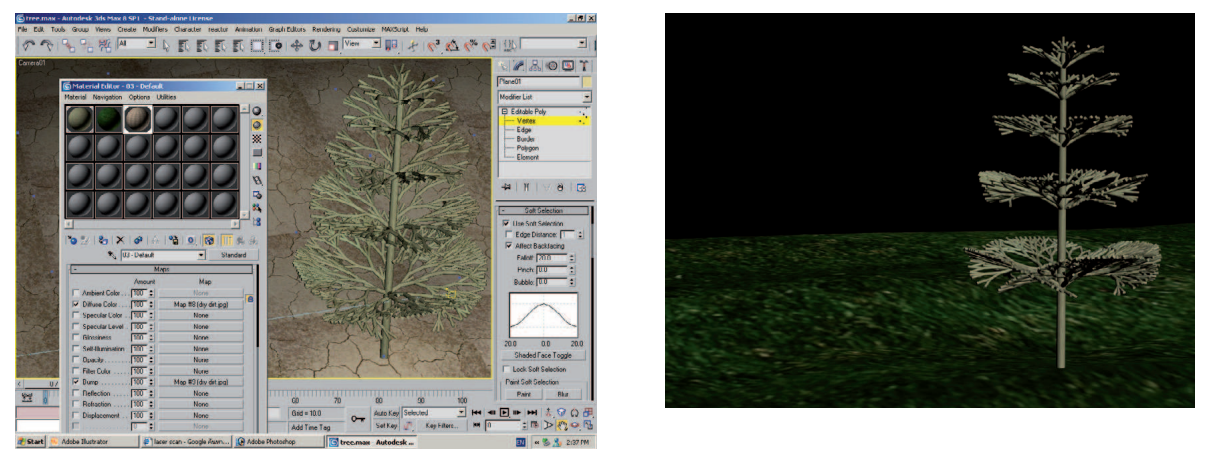

Figure 14: (a) A 3D FractaL Tree Krajong tree model was exported to Autodesk 3ds Max [ $<$ http://usa.autodesk.com/adsk/servlet/index\%3Fid=5659302\&siteID=123112 $>$ ] on one of their background images of cracked mud showing some of their palette of tools and a second one with re-coloring placed on a lawn and sky background. Autodesk 3ds Max is a "modeling, animation, and rendering solution [that] is used to produce top-selling games and award-winning film and video content. (...) Enhanced toolsets let you create your 3D environment the way you want, manage complex scenes, and [use in] ... game development, television, film, and digital publishing industries."

Example 3: Lelewadee was chosen because its branching is one of the simpler, quite uniformly trifurcating phytoarchitectures that we could find (see Figure 15).
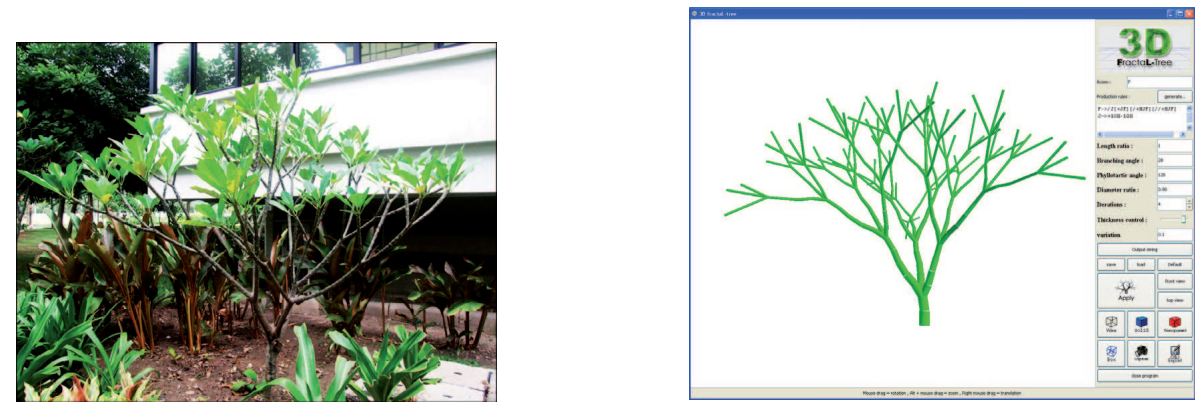

Figure 15: (a) A Lelewadee tree on the NECTEC campus and (b) the computer model.

The L-system rules used for the Lelewadee tree are: [LELEWADEE_TREE.TXT; [plant parameters]; length ratio $=0.95$; branching angle $=7.5$; phyllotactic angle $=30$; diameter ratio $=0.90$; iteration=4; axiom=F; [grammar] F- $>/ / / / / / J[+++J F][/ / / /++++H J F][\backslash \backslash \backslash \backslash+++++H J F] ; J->\backslash-\mathrm{H} \backslash+\mathrm{H}]$.

Examples 4 and 5: Jeff Knisley, Chair of Mathematics at East Tennessee State University, used $3 D$ FractaL Tree in a Symbiosis mathematical biology program, funded by the Howard Hughes Medical Institute, to encourage collaboration between mathematics and biology to address the previously cited NRC report Bio 2010 (2003). His students developed the weeping elm [rules: [plant parameters] length ratio $=1.0$; branching angle $=7.5$; phyllotactic angle $=4.9$; diameter ratio $=0.9$; it eration $=1$; axiom $=\mathrm{F}$; variation $=0.1$; grammar] 
F- $>/ / / / / \mathrm{J}[+++\mathrm{JF}][/ / /++++\mathrm{HJF}][\backslash \backslash \backslash+++++\mathrm{HJF}] ; \mathrm{J}->\backslash-\mathrm{H} \backslash+\mathrm{H}$ and the floret of broccoli [rules: [plant parameters]; length ratio $=0.55$; branching angle $=110$; phyllotactic angle $=30$; diameter ratio $=0.55$; iteration $=1$; axiom $=\mathrm{F}$; variation $=0.1$; [grammar $] \mathrm{F}->\mathrm{G}[+/ \mathrm{F}][-/ \mathrm{F}] / / /[-\mathrm{F}][+\mathrm{F}][/ \mathrm{F}] ; \mathrm{G}->\mathrm{G}]$. Because these are familiar structures we do not illustrate them here but encourage you to download the software, build an initial version with these values, and iteratively improve your model to match a local example or a downloaded image from which you can make measurements.

\section{L-system Rules}

$3 D$ FractaL Tree employs edge re-writing rather than node rewriting (see Prusinkiewicz and Lindenmayer, 1990). While either approach could be used to generate the same ultimate morphology, we have implemented and solely focused on edge re-writing because we found it: (i) easier to write such rules; (ii) made more sense intuitively to break a branch into sections proportional to the N0/N1 ratio and then generate the bifurcation; and, (iii) easier to implement one of the two kinds of rules throughout.

\section{Deterministic versus Stochastic Models}

While the deterministic model described above has been successfully used in classes, we were dissatisfied that some computer models did not satisfactorily represent some of the variation of branching of structure within our photographed trees; i.e., the deterministic L-system rules were rigidly self-similar in the composition of the tree. Thus, in Figure 16, we illustrate our stochastic version by illustrating a case where we can randomly choose between multiple L-system rules (in this case, the probability between three different choices of rules is equal).

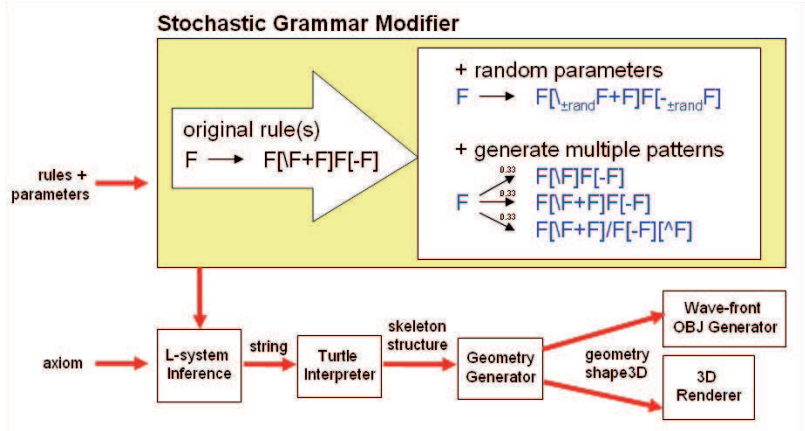

Figure 16: Implementation of the Stochastic Grammar Modifier version of L-system rules in 3D FractaL Tree. This allows us to produce realistic variation in the complexity of the branching structure. The particular rules and their probabilities of occurrence are determined in the L-system rule editor. The degree of overall variation can be set by using a slider bar on the main screen of $3 D$ FractaL Tree. 


\section{Discussion of Computer Model}

The traditional L-systems may result in plant models with high similarity to natural plants. In the past, L-systems usually tried to fit the model to the target plant by adjusting parameters without the consideration of real measurements. Herein, we have proposed a new system in $3 D$ FractaL Tree that takes into account the information retrieved from a target plant which leads to a much greater morphological likeness and a more predictable model. However, differences between the model constructed from our system and a target plant remains. This is because of the complexity in nature that affects development in unpredictable ways (weather factors like snow, ice, wind, lightning, etc. that stress or break plants as well as drought and floods that result in very different growth rates in different years). These can not be easily interpreted and calculated for each individual plant, over the course of the tree's lifetime which may exceed many human generations (bristlecone pines are thought to live four to six thousand years). Furthermore, beyond the environmental factors affecting one tree's development and senescence over its lifetime, some obstacles may be caused by the evolutionary forces endured by plants that have attempted to survive in stressful conditions over populations through many generations. The Stochastic L-systems may be used to construct models regarding these factors which may be random in nature, but which result in significant differences between the model and the target one received. Thus, our deterministic method is suitable to solve the generic growth pattern of plants, but our stochastic version can generate even greater approximations to reality. Our proposed system may be applied to various types of organisms, different systems such as the bronchii of lungs, or even to predict the folding of H-P lattice/fractal models of proteins. As already indicated, tree models themselves, and in particular, 3D FractaL Tree, may be used in practical applications such as horticulture, fruit tree pruning, and landscape architecture as well as in film and television to create realistic images.

\section{Evolutionary Morphospace}

David Raup (1962) introduced the idea of a morphospace in examining the morphology of both contemporary and extinct seashells. He concluded that, contrary to previous opinion, we should not be so impressed by the diversity of forms of biological organisms, but instead should ask why haven't more forms existed? This enigma has persisted to today; e.g., the cover story of a recent issue of Science explored: "why the biological forms [of plants] we see in nature represent such a small part of theoretical possibilities" (Prusinkiewicz et al., 2007). Niklas (1999) asserts that the fundamental debate about plant models is whether selection ("persistent and strong environmental sorting") is the major evolutionary force in accounting for the recognizable morphology of species or whether differences between species are "largely undetected by natural selection." Therein he constructs a three dimensional morphospace of land plants using three variables: the bifurcation angle, the phyllotactic angle, and the probability of branching (see Figure 16 for the richness of morphospace that is possible with 3D FractaL Tree). Niklas (1999) explored whether concurrent optimization of numerous selection factors such as "harvest[ing] solar radiance, conserv[ing] body fluids, and dispers[ing] spores or propagules ... require morphological or anatomical reconciliations." He concluded that these "design requirements ... require some degree of compromise and 
that the physical manifestations of equally good compromises are diverse is evident from the ability of morphologically or anatomically dissimilar plant species to survive in similar environments." We believe that this perspective is one that students can easily examine.

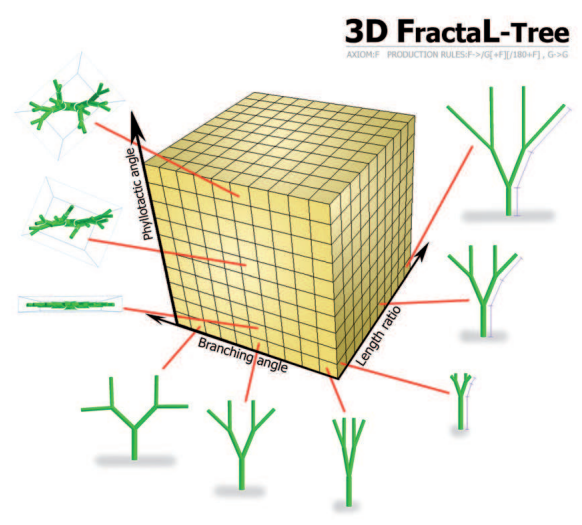

Figure 17: Morphospace possible with 3D FractaL Tree.

Students are encouraged to consider even more factors that might define the shape of a given plant. Pearcy et al. (2005) presented nine problems or factors, that plants must resolve:

(1) Biomechanical constraints

(2) Hydraulic constraints

(3) Developmental constraints

(4) Allocational Constraints

(5) Maximization of whole-plant light capture, carbon gain

(6) Maximization of competitive ability

(7) Maximization of reproduction;

(8) Minimization of risk due to damage

(9) Minimization of stress due to high light and temperature

By engaging students in carefully measuring and modeling multiple trees and considering plants as organisms simultaneously solving numerous problems, they typically raise even more context specific questions such as the impact of terrain, soil, prevailing winds, pollutants, crowding, shading due to proximity of buildings, etc. These questions usually lead to interesting discussions of plant physiology, development, ecology, and evolution.

Once students have a model and have tried to examine its structure in terms of problems that a tree faces in surviving well and reproducing, we believe that it is important for them to consider 
the theoretical models that have been reported in the literature. 3D FractaL Tree addresses two theories of tree development and evolution out of nine theories that have been described by Sattler and Rutishauser (1997). While we personally think that some of their models are much less well supported than others, we believe that it is very important for students to examine each of the theories based on: (1) evidence that they have acquired and that has been reported in the primary literature, and; (2) their own expectations of what a good theory will do for them. Also, we believe that it is important for students to appreciate the role of theory, controversy and heterodoxy in science.

The statistician Leo Breiman (1995) humorously notes (in a fashion accessible to students) that the four main uses of theory are:

(1) Comfort: We knew it worked, but it's nice to have a proof.

(2) Insight: Aha! So that's why it works.

(3) Innovation: At last, a mathematically proven idea that applies to data.

(4) Suggestion: Something like this might work with data.

In order to help students develop their own intuition about the role of theory, we believe that three additional insights can be helpful in extending their experience in matching their measurements and models. First, the paleontologist Dolf Seilacher (in Willis, 1995) states that the most important use of theory is as a lens: "I wouldn't have seen it, if I hadn't believed it." Many students report that once they understood a little bit about fractals and their generative rules of self-similarity that they could see and apply it to many other examples in their immediate surroundings. Second, the philosopher of biology William Wimsatt (2007) believes that scientists go astray when they too rigidly adopt the Karl Popper type asymmetric relationship of falsification over confirmation. This is because, Wimsatt notes, modeling is a very different sort of activity. We know that every model that we build is false even before we start to work with it because we have simplified assumptions in order to construct a model. But where is the power of these models, why does the model capture so robustly much of what we observe? If there is such a match between the theoretical model and an observed specimen, we are applying Occam's razor as social commitment to parsimonious explanatory models. Thus, Wimsatt (2007) states that "False Models [are a] Means to Truer Theories". Third, John Casti (1997) believes that simulation and modeling are most powerful because of the element of surprise. Once you have a model that works to a sufficient degree, it allows you to explore the fuller application of the model and generate things that simply do not square with your intuition. This is particularly appropriate in the case of studying Morphospace because a model can produce geometries of plants that have never existed. This lets scientists and students alike ask "why?"

\section{Future Directions}

As previously cited, Brian Enquist and Karl Niklas (2002) have reviewed theoretical approaches to allometric relations between "intraspecific and interspecific scaling relationships among seed 
plant leaf, stem, and root biomass." They have already extended this approach somewhat (Price, Enquist, and Savage, 2007). We will depend upon such extensions to inform improvements on $3 D$ FractaL Tree. Recently, Brian Enquist, John Sperry, Peter Reich, and Van Savage (2007) from the University of Arizona state that they will produce a model that will "Combin[e] Theories For Plant Architecture, Allometry, and Traits to Develop the Next Generation of Scaling Theory:"

This proposal will develop a synthetic and predictive theory for plant biology that links physiological processes from the level of plant cells and hydraulic vascular systems to that of whole forests and the biosphere. Using theoretical, laboratory, and field based techniques, the research brings together plant physiologists, ecologists and theoretical biologists to advance existing theory in order to develop a unified and quantitative scaling approach. The work will ultimately help biologists determine which attributes of plants to measure and how to put these measurements together in order to predict plant growth, water transport, and carbon flux.

These predictions will crucially inform how nations can anticipate and respond to anthropogenically caused global warming and extinction crises. Results from this research could provide a necessary tool in the development of a predictive theory for connections between functional plant bioogy and ecosystem science. For example, the proposed work will likely lead to more accurate calculations of terrestrial carbon budgets, earlier genetic selection programs, appropriate species choices that correspond to different management goals, and prescriptions for pruning or spacing in forests, row crops, and orchards. Results should also inform how ecosystem and ecological processes are affected by changes in individual plants. Graduate students and postdoctoral researchers involved in the project should be trained to integrate new theoretical developments with empirical tests to advance a deeper understanding of biological processes.

Please note the explicit role of education and students in their proposal. We cite this as support for building such explicit understanding of and appreciation for theoretical models and empirical measurement at the undergraduate level as they will become this next generation of "graduate students and postdoctoral researchers." As these models become available, we will adjust $3 D$ FractaL Tree to include suggested measurements and calculations. In particular, we want to make measurements from our 3D representations and allometric calculations available and transparent on the human interface. We urge readers to explore some recent literature that explores some of these avenues (Ogle and Pacala, 2009; Niklas and Cobb, 2008; Robinson, 2007; Zens and Webb, 2002). In particular, we believe that students will be motivated by the connection of making measurements on trees in their immediate environment, analyzing those measurements in the context of theoretical models, beautifully visualizing their models in three dimensions, and especially relating their work to their sense of an important real world problem: global warming. 


\section{Conclusion}

The power of engaging students in nondestructive measurement of individual trees, modeling their morphology with $3 D$ FractaL Tree, comparing their model with their original plant, quantitatively constructing relationships between such internal features as crown area and trunk diameter, considering variables that might affect the trajectories of branches in three dimensional space, and comparing intraspecies and interspecies variation in similar and different habitats is thus multifaceted. 3D FractaL Tree helps students explore questions in their attempts to explain why the biological forms that we see in nature represent such a small part of theoretical possibilities of current interest (Prusinkiewicz et al.'s models (p. 1452, published online 24 May 2007; and see the cover) and combine genetic and theoretical studies on inflorescence architecture. By showing how interactions between development and selection operate within higher-dimensional fitness spaces, students can similarly explore "constraints on the evolution of biological forms."

\section{Acknowledgements}

Support for the Thai team is from the NECTEC grant number C24803. Generous professional support has been provided by Chularat Tanprasert, Head, Knowledge Elicitation and Archiving Laboratory, and Piyawut Srichakul, Director, the Knowledge Engineering Technology Program. Partial support for this work was provided by Claudia Neuhauser, Department of Ecology and Evolution, University of Minnesota via a Howard Hughes Medical Institute subcontract "NUMB3R5 COUNT!: Numerical Undergraduate Mathematical Biology Education: exploRing with Statistics, Computation, mOdeling, and qUaNtitative daTa) to the BioQUEST Curriculum Consortium and a Mathematics Association of America grant to the BioQUEST Curriculum Consortium for the Biological ESTEEM Project (Excel Simulations and Tools for Exploratory, Experiential Mathematics). Hsiao Honda, Pauline Hogeweg, and Henry Horn have served as primary personal motivators for sustaining an interest by the senior author in the evolution of phytoarchitecture since 1968 . Yaffa Grossman and Rama Viswanathan have provided numerous insights into plant modeling and computer visualization.

\section{References}

[1] M. T. Allen, P. Prusinkiewicz, T. M. DeJong. Using L-systems for modeling source-sink interactions, architecture and physiology of growing tree: The L-Peach model. New Phytologist. 166, 2005, No. 3, 869-880.

[2] R. Aratsui. Leonardo was wise: Trees conserve cross-sectional area despite vessel structure. J. Young Investigators, 1, 1998, 1-23.

[3] J. K. Bailey, R. K. Bangert, J. A. Schweitzer, R. T. Troter III, S. M. Shuster, T. G. Whitman. Fractal geometry is heritable in trees. Evolution, 58, 2004, No. 9, 2100-2102. 
[4] D. Barthélémy, Y. Caraglio. Plant architecture: A dynamic, multilevel and comprehensive approach to plant form, structure and ontogeny. Annals of Botany, 99, 2007, No. 3, 375407. Available online at http://aob.oxfordjournals.org/cgi/content/abstract/mcl260v1.

[5] F. S. Berezovskava, G. P. Karev, O. S. Kisliuk. R. G. Khlebopros, Y. L. Tsel'niker. A fractal approach to computer-analytical modeling of tree crowns. Trees, 11, 1997, 323-327.

[6] N. Bessonov, V. Volpert. Dynamic models of plant growth. Mathematics and Mathematical Modelling. Editions Publibook Universite, Paris, France, 2008.

[7] L. Breiman. Reflections after refereeing papers for NIPS. In David Wolpert, Ed., The Mathematics of Generalization. Santa Fe Institute Studies in the Sciences of Complexity Volume XX. Addison-Wesley: Reading, MA, 1995.

[8] J. L. Casti. Would-Be worlds: How simulation is changing the frontiers of science. John Wiley and Sons: New York, NY, 1997.

[9] J. E. Cohen. Mathematics is biology's next microscope, only better; Biology is mathematics next physics, only better. Public Library of Science Biology, 2, 2004, No. 12, 2017-2023.

[10] O. Deussen, B. Lintermann. Digital design of nature: Computer generated plants and organics. New York: Springer-Verlag, 2005.

[11] A. E. Dimond. Pressure and flow relations in vascular bundles of the tomato plant. Plant Physiology, 41, 1966, 119-131.

[12] J. Elkins. The object stares back: On the nature of seeing. Harcourt Brace and Company: San Diego, CA, 1996.

[13] B. J. Enquist, K. J. Niklas. Global allocation rules for patterns of biomass partitioning in seed plants. Science, 295, 2002, No. 5559, 1517-1520.

[14] B. Enquist, J. Sperry, P. Reich, V. Savage. Combining theories for plant architecture, allometry, and traits to develop the next generation of scaling theory. NSF Emerging Frontiers Award \#0742800. Start Date: December 1, 2007 - Expires: November 30, 2010 (Estimated); NSF Program: THEORETICAL BIOLOGY, 2007.

[15] FSPM07. Fifth international workshop on functional structural plant models. Napier, New Zealand, 4-9 November, 2007.

[16] J. Fisher, H. Honda. Branch geometry and effective leaf area: A study of Terminaliabranching pattern: Theoretical ideas. American J. Botany, 66, 1979, 633-644.

[17] C. Godin, O. Puech, F. Boudon, H. Sinoquet. Space occupation by tree crowns obey fractal laws: Evidence from $3 D$ digitized plants. In Godin, C. Hanan, J. Kurth, W. Lacointe, A. Takenaka, A. Prusinkiewicz, P. DeJong, T. M. Beveridge, C. Andrieu, B., Eds. Proceedings 
of Proceedings of the 4th International Workshop on Functional-Structural Plant Models. Montpellier, 2004, 79-83. Proceedings of the 4th International Workshop on FunctionalStructural Plant Models, 7-11/06/2004, Montpellier.

[18] C. Godin, E. Costes, H. Sinoquet. A method for describing plant architecture which integrates topology and geometry. Annals of Botany, 84, 2004, 343-357.

[19] Y. Grossman, T. De Jong, et al. Peach. In Jungck et al., Eds., The BioQUEST Library, Academic Press: San Diego, 2003.

[20] M. Hiratsuka, T. Toma, M. Yamada, I. Heriansyah, Y. Morikawa. A general allometric equation for estimating biomass in Acacia mangium plantations. In Proceedings of the 2003 International Conference on Tropical Forests and Climate Change, University of the Philippines Los Banos, Laguna, Philippines, 2003, 212-218.

[21] P. Hogeweg, B. Hesper. A model study on biomorphological description. Pattern Recognition, $6,1974,165-179$.

[22] H. Honda. Description of the form of trees by the parameters of a tree-like body: Effects of the branching angle and branch length on the shape of the tree-like body. J. Theoretical Biology, 31, 1971, 331-338.

[23] H. S. Horn. Adaptive geometry of trees. Princeton University Press: Princeton, NY, 1971.

[24] J. R. Jungck. Ten equations that changed biology. Bioscene: Journal of College Biology Teaching, 23, 1997, No. 1, 11-36. Available online at http://papa.indstate.edu/amcbt/volume_23/

[25] J. R. Jungck, E. D. Stanley, S. J. Everse, V. Vaughan, Eds. The BioQUEST Library. Academic Press: North Reading, MA, 2003.

[26] J. R. Jungck. The biological ESTEEM collection: Excel simulations and tools for exploratory, experiential mathematics. BioQUEST Notes, 14, 2005, No. 1, 1-2, and 11-17.

[27] J. R. Jungck. Challenges, connections, complexities: Educating for collaboration. Chapter in Lynn Steen, Ed., Math \& Bio2010: Linking Undergraduate Disciplines. The Mathematical Association of America: Washington, DC., 2005, 1-12.

[28] J. R. Jungck. Fostering figuring and fascination: Engaging learners through alternative aesthetics. In J. R. Jungck, Er. Mazur, Wi. Schmidt, T. Schuller, Eds., Criticism of Contemporary Issues: Education. Serralves Museum of Art, Fundacao Serralves: Porto, Portugal, 2008, 1954 and $93-126$.

[29] C. E. Knapp. Review of Last child in the woods: Saving our children from nature-deficit disorder (Revised edition), by Richard Louv. 2008. Chapel Hill, NC: Algonquin Books. 390 pages. Paperback. \$14.95. ISBN13: 978-1-56512-605-3. Journal of Environmental Education, 40, 2009, No. 2, 63-64. 
[30] A. Lindenmayer. Developmental systems without cellular interaction, their languages and grammars. J. Theoretical Biology, 30, 1971, 455-484.

[31] A. Lindenmayer. Developmental systems and languages in their biological context. In G. T. Herman \& G. Rozenberg, Eds., Developmental systems and languages. Amsterdam: NorthHolland Publishing, 1975, 1-40. 0-7204-2806-8

[32] A. Lindenmayer. Growing fractals and plants. In Heinz-Otto Peitgen, Hartmut Jürgens and Dietmar Saupe, Eds. Chaos and Fractals, Second Edition. New Frontiers of Science. Springer: New York, 2004, 329-376. ISBN 978-0-387-20229-7

[33] R. Louv. A brief history of the children \& nature movement. J. Sci. Educ. Technol, 17, 2008, 217-218. DOI 10.1007/s10956-007-9085-z

[34] B. Mandelbrot. Fractals: Form, chance and dimension. W. H. Freeman and Co.: San Francisco, 1977.

[35] K. A. McCulloh, J. S. Sperry, R. F. Adler. Water transport in plants obey Murray's law. Nature, 401, 2003, 939.942.

[36] K. A. McCulloh, J. S. Sperry, R. F. Adler. Murray's law and the hydraulic vs mechanical functioning of wood. Functional Ecology, 18, 2004, 931.938.

[37] M. Mesterton-Gibbons, M. J. Childress. Constraints on reciprocity for non-sessile organisms. Bulletin of Mathematical Biology, 58, 1996, No. 5, 861-875.

[38] National Research Council. Bio 2010: Transforming undergraduate education for future research biology. National Academies Press: Washington, DC, 2003.

[39] K. J. Niklas. Computer simulations of branching-patterns and their implications on the evolution of plants. In L. J. Gross, R. M. Miura, Eds. Some Mathematical Questions in Biology: Plant Biology, Lectures on Mathematics in the Life Sciences, 18, 1986, 1-50 (American Mathematical Society).

[40] K. J. Niklas. Evolutionary walks through a land plant morphoscape. J. Experimental Botany, 50, 1999, No. 330, 39-52.

[41] K. J. Niklas, E. D. Cobb. Evidence for “diminishing returns" from the scaling of stem diameter and specific leaf area. Am. J. Botany, 95, 2008, 549-557.

[42] K. Ogle, S. W. Pacala. A modeling framework for inferring tree growth and allocation from physiological, morphological and allometric traits. Tree Physiol., 29, 2009, 587-605.

[43] R. W. Pearcy, H. Muraoka, F. Valladares. Crown architecture in sun and shade environments: Assessing function and trade-offs with a three-dimensional simulation model. New Phytologist, 166, 2005, No. 3, 791-800. 
[44] C. A. Price, B. J. Enquist, V. M. Savage. A general model for allometric covariation in botanical form and function. PNAS, 104, 2007, 13204-13209.

[45] P. Przemyslaw, J. Hanan. Lindenmayer systems, fractals, and plants. Lecture Notes in Biomathematics, volume 79. Springer-Verlag, New York, 1989.

[46] P. Prusinkiewicz, A. Lindenmayer. The algorithmic beauty of plants. New York: SpringerVerlag, 1990. (Available on-line in high quality pdf at (http://algorithmicbotany.org/papers/\#abop)).

[47] P. Prusinkiewicz, Y. Erasmus, B. Lane, L. D. Harder, E. Coen. Evolution and development of inflorescence architectures. Science, 316, 2007, No. 5830, 1452-1456.

[48] D. M. Raup. Computer as aid in describing form in gastropod shells. Science, 138, 1962, $150-152$.

[49] P. de Reffye. Computer simulation of plant growth. In Clifford A. Pickover and Stuart K. Tewksbury, Eds. Frontiers of scientific visualization. John Wiley \& Sons, Inc.: New York, NY, USA, 1994, 145-179.

[50] D. Robinson. Implications of a large global root biomass for carbon sink estimates and for soil carbon dynamics. Proc. R. Soc. B, 274, 2007, 2753-2759.

[51] A. Szalay, J. Gray. 2020 computing: Science in an exponential world. Nature, 440, 2006, 413-414. [Microsoft Science 2020.]

[52] R. Sattler, R. Rutishauser. The fundamental relevance of morphology and morphogenesis to plant research. Annals of Botany, 80, 1997, 571-582.

[53] Seits, I.S. Antonova. Applying multidimensional statistics to tree architecture analysis. In Godin, C. Hanan, J. Kurth, W. Lacointe, A. Takenaka, A. Prusinkiewicz, P. DeJong, T. M.Beveridge, C. Andrieu, B., Eds. Proceedings of Proceedings of the 4th International Workshop on Functional-Structural Plant Models. Montpellier, 2004, 70-74. Proceedings of the 4th International Workshop on Functional-Structural Plant Models, 7-11/06/2004, Montpellier.

[54] I. Shlyakhter, M. Rozenoer, J. Dorsey, S. Teller. Reconstructing 3D tree models from instrumented photographs. IEEE Computer Graphics and Animations, xx, 2001, 1-9.

[55] S. Wegrzyn, J.-C. Gille, P. Vidal. Developmental systems: At the crossroads of system theory, computer science, and genetic engineering. Springer-Verlag: New York, 1990.

[56] A. Weisstein, Ed. The Biological ESTEEM project (Excel simulations and tools for exploratory, experiential mathematics), 2009. ( $<\mathrm{http} / /$ bioquest.org/esteem $>$ ).

[57] D. Willis, The sand dollar and the slide rule. Addison-Wesley Publishing Co.: North Reading, MA, 232 pp, 1995. ISBN 0-201-63275-6 \$23 (\$27 postpaid) from 
[58] W. Wimsatt. False models as means to truer theories. Chapter 6 in his book:Re-engineering philosophy for limited beings: Piecewise approximations to reality. Harvard University Press: Cambridge, MA, 2007.

[59] M. S. Zens, C. O. Webb. Sizing up the shape of life. Science, 295, 2002, No. 5559, 1475. 